\title{
Raiva em morcegos não hematófagos em São José do Egito, semiárido
}

\section{Pernambucano}

\author{
Rabies in non-hematophagous bats in São José do Egito, semi-arid of Pernambuco \\ Rabia en murciélagos no hematófagos en São José do Egito, semiárido de Pernambuco
}

Recebido: 02/08/2021 | Revisado: 07/08/2021 | Aceito: 09/08/2021 | Publicado: 14/08/2021

Luiz Augustinho Menezes da Silva

ORCID: https://orcid.org/0000-0003-3776-5202

Universidade Federal de Pernambuco, Brasil

E-mail: laugustinhoms@gmail.com

Ednaldo de Souza Gomes

ORCID: https://orcid.org/0000-0003-3906-2703

Secretaria Municipal de Saúde, Brasil

E-mail: ednaldosousagomes@yahoo.com.br

Emmanuel Messias Vilar Gonçalves da Silva

ORCID: https://orcid.org/0000-0003-0108-7841

Universidade Federal da Paraíba, Brasil E-mail: messiashp@gmail.com

Teone Pereira da Silva Filho

ORCID: https://orcid.org/0000-0001-8664-3151

Universidade Federal de Pernambuco, Brasil E-mail: teonefilho@gmail.com

Roseli Rodolfo da Silva

ORCID: https://orcid.org/0000-0002-7500-0334

Universidade Federal de Pernambuco, Brasil

E-mail: rose_saia@hotmail.com

\begin{abstract}
Resumo
Diversas espécies de mamíferos no Brasil já foram diagnosticadas com o vírus da raiva dentre animais de companhia, de criação e silvestres. Entre os quirópteros destaca-se o hematófago Desmodus rotundus, entretanto, o registro de positivos não se restringe a essa guilda alimentar. Diante disso, esse trabalho tem como objetivo descrever os casos positivos de morcegos não hematófagos para raiva no município de São José do Egito, localizado no semiárido Pernambucano. Foi realizada uma análise de registros com dados de amostras enviadas para análise rábica pela vigilância sanitária do Município e pelo trabalho de monitoramento dos quirópteros realizado no município entre outubro/2010 e julho/2012. Foram encontrados em quatro anos, 11 espécimes de três espécies (Molossus molossus, Myotis lavali e Glossophaga soricina), positivas para raiva na área urbana de São José do Egito com uma maior frequência para M. molossus. Em um dos casos ocorreu à agressão a um munícipe. Os espécimes foram encontrados em condições atípicas mantendo atividade diurna, caídos no chão ainda com vida ou mortos na rua e em seus abrigos. Os registros mostram que, apesar de não haver casos em cães e gatos, a raiva circula na área urbana do município em situação próxima aos munícipes e que o monitoramento é necessário para evitar contágio a humanos e animais domésticos.
\end{abstract}

Palavras-chave: Área urbana; Chiroptera; Diagnóstico; Lyssavirus.

\begin{abstract}
Several species of mammals in Brazil have already been diagnosed with the rabies virus among companion, farm and wild animals. Among the bats, the hematophagous Desmodus rotundus stands out, however, the record of positives is not restricted to this food guild. Therefore, this work aims to report the positive records of rabies in bats in the municipality of São José do Egito, located in the semi-arid region of Pernambuco. An analysis of records with data on samples submitted for rabies analysis by sanitary surveillance and by the work of monitoring the bats performed in the municipality between on October / 2010 and July / 2012 was carried out. Eleven specimens of three species (Molossus molossus, Myotis lavali and Glossophaga soricina) were found in four years, positive for rabies in St. Joseph of Egypt with a higher register for M. molossus. In one of the cases it happened to the aggression to a citizen. The specimens were found in atypical conditions maintaining daytime activity, lying on the ground still alive or dead on the street and in their shelters. The records show that rabies circulates in the urban area of the municipality and that monitoring is necessary to avoid contagion to humans and domestic animals.
\end{abstract}

Keywords: Urban area; Chiroptera; Diagnosis; Lyssavirus. 


\begin{abstract}
Resumen
Varias especies de mamíferos en Brasil ya han sido diagnosticadas con el virus de la rabia entre animales de compañía, de granja y salvajes. Entre los murciélagos destaca el hematófago Desmodus rotundus, sin embargo, el registro de positivos no se limita a este gremio alimentario. Por tanto, este trabajo tiene como objetivo informe de los registros de murciélagos positivos para la rabia en el municipio de São José de Egito, ubicado en el semiárido de Pernambuco. Se realizó un análisis de registros con datos sobre muestras enviadas para análisis rábico por la vigilancia sanitaria y por el trabajo de monitoreo de los quirópteros realizado en el municipio entre octubre / 2010 y julio / 2012. Se encontraron en cuatro años, 11 especímenes de tres especies (Molossus molossus, Myotis lavali y Glossophaga soricina), positivas para rabia en São José do Egito con un mayor registro para M. molossus. En uno de los casos se produjo la agresión a un ciudadano. Los especímenes fueron encontrados en condiciones atípicas manteniendo actividad diurna, caídos en el suelo aún con vida o muertos en la calle y en sus abrigos. Los registros muestran que la rabia circula en el área urbana del municipio y que el monitoreo es necesario para evitar contagio a humanos y animales domésticos.
\end{abstract}

Palabras clave: Área urbana; Chiroptera; Diagnóstico; Lyssavirus;

\title{
1. Introdução
}

A raiva é uma zoonose causada por um vírus do gênero Lyssavirus (Rhabdoviridae), caracterizada como uma encefalite aguda e apesar de ser uma doença reconhecida desde a antiguidade, à preocupação com a raiva ainda persiste, por causa de sua progressão quase sempre fatal (Escobar et al., 2015; Fooks et al., 2017). Diversas espécies de mamíferos no Brasil já foram diagnosticadas com o vírus da raiva, dentre animais domésticos (como cães e gatos), de criação (cavalos, bois, cabras, dentre outros) e silvestres (raposas, saguins e morcegos) (Kotait et al., 2007; 2010; Escobar et al., 2015). A doença representa um grande risco aos animais de produção, como bovinos e equinos dentre outros, e requer bastante atenção devido ao fato da sua alta letalidade em humanos (Quevedo et al., 2020).

No grupo dos quirópteros destaca-se o morcego hematófago Desmodus rotundus (E. Geoffroy, 1810) como um importante dispersor do vírus, sendo esta espécie a principal agente da transmissão da raiva no ciclo rural (Lopes et al., 2021). Entretanto, o registro de morcegos positivos não se restringe a esse guilda alimentar (Sodré et al., 2010), há ocorrências em espécies insetívoras, frugívoras, nectarívoras, onívoras e carnívoras (Sodré et al., 2010; Fahl et al., 2015).

A circulação do Lyssavirus em quirópteros pode tornar mais propenso os surtos de raiva em humanos e animais domésticos quando há contato direto com morcegos infectados (Escobar et al., 2015), onde registros de raiva em morcegos nas áreas urbanas já foram relatados para várias regiões do Brasil (Fahl et al., 2015). Além disso a variante do vírus da raiva de morcegos (AgV3) já foi registrada em outros grupos de mamíferos em áreas urbanas e rurais (Ferreira et al., 2020). Relatos de morcegos positivos em ambientes urbanos são de fundamental importância para melhor entender a dinâmica da doença neste ambiente, a fim de reconhecer as espécies mais envolvidas no ciclo, facilitando assim o desenvolvimento de medidas profiláticas adequadas e otimizando o trabalho da vigilância epidemiológica. Sendo assim, esta pesquisa visa descrever os relatos de raiva em morcegos no município de São José do Egito, sertão de Pernambuco.

\section{Metodologia}

São José do Egito está localizado entre as coodenadas de latitude $07^{\circ} 28^{\prime} 44^{\prime \prime}$ sul e longitude $37^{\circ} 16^{\prime} 28^{\prime \prime}$ oeste, a 585 metros acima do nível do mar, no Sertão Pernambucano, mais especificamente inserido na Microrregião do Pajeú onde ocupa uma área de 792,00 km² (Figura 1), com uma população de 31.838 habitantes (IBGE, 2020).

Os registros foram obtidos durante o trabalho "Monitoramento de morcegos em áreas urbanas e rurais no município de São José do Egito: subsídios para o controle da raiva" realizado em parceria com o município, entre outubro de 2010 a julho de 2012, e pela análise do banco de dados da Vigilância Sanitária Municipal. Atividades educacionais foram fundamentais para divulgar as ações do trabalho e auxiliar na busca por espécimes em condições atípicas e/ou em seus abrigos. Quando possível, os quirópteros foram identificados seguindo a literatura específica (Vizotto \& Taddei, 1973; Gregorin \& Taddei, 2002; 
Gardner, 2007; Diaz et al., 2011; Miranda et al., 2011) e em seguida foram encaminhados para o Laboratório Nacional Agropecuário em Pernambuco (LANAGRO/PE) para diagnóstico por imunofluorescência direta (IFD) e prova biológica (PB). Ambas são recomendadas pela Organização Mundial de Saúde como testes diagnósticos da doença (Brasil, 2008).

Figura 1. Localização do município de São José do Egito dentro da Microrregião do Pajeú no Estado de Pernambuco.

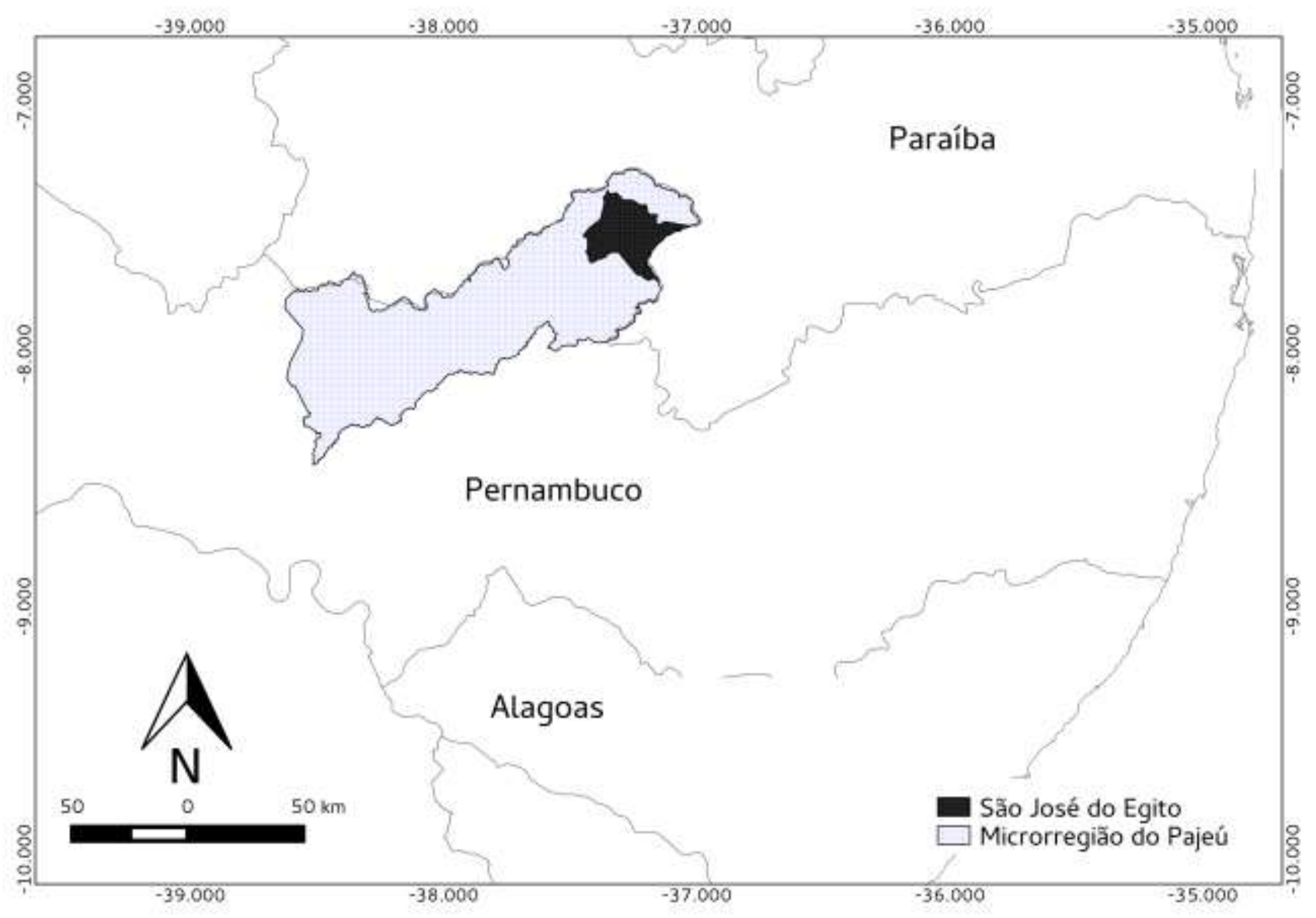

Fonte: Autores.

\section{Resultados}

Em quatro anos foram encontrados 11 morcegos positivos para raiva, todos na área urbana do município. Em três relatos não foi possível identificar a espécie, registrado apenas nas fichas como não hematófago, pois os indivíduos foram eliminados logo após o diagnóstico não sendo encaminhados para a identificação. Os quirópteros identificados pertencem as seguintes espécies: seis Molossus molossus (Pallas, 1766), um Myotis lavali (Moratelli, Peracchi, Dias \& Oliveira, 2011) e um Glossophaga soricina (Pallas, 1766); sendo as duas primeiras insetívoras (Molossidae e Vespertilionidae respectivamente), enquanto a terceira é nectarívora/frugívora (Phyllostomidae). Já que espécimes de Myotis nigricans foram revalidados como Myotis lavali pode se considerar a ocorrência dessa espécie também em área urbana, porém com uma distribuição menos ampla do que as outras espécies aqui registradas (Moratelli \& Wilson, 2013), todos os espécimes de M. nigricans coletados durante o trabalho e depositados na coleção foram analisados posteriormente e identificados como M. lavali (Moratelli et al., 2011; Diaz et al., 2016). 
Caso 01 (Espécie não identificada - ENI) - No dia 16/06/2009, próximo a uma praça no bairro Ipiranga, um morcego que voava atipicamente pelo horário da manhã colidiu com a moto de um homem, que coletou o animal e o encaminhou para a Vigilância Sanitária. Sendo esse o primeiro registro de positividade da raiva em quirópteros na cidade.

Caso 02 (ENI) - Às 15h00min do dia 30/08/2009, um morador da Vila Érica, localizada no bairro Ipiranga, encontrou um morcego tentando voar junto ao portão de uma residência. Ele coletou o espécime, sacrificou e enviou para a Vigilância Sanitária, que destinou o animal para a análise rábica.

Caso 03 (ENI) - Em 07/11/2009, pelo horário da manhã, foi encontrado um morcego em frente à uma residência no bairro Novo Horizonte, área central do município. O animal tentava se deslocar em uma parede na área do jardim (permanecendo assim por aproximadamente 30 minutos), até que foi capturado pelo proprietário e encaminhado para o laboratório.

Caso 04 - Molossus molossus - Em 20/01/2010, no período vespertino, um indivíduo de M. molossus foi localizado caído no solo por um agente ambiental. $\mathrm{O}$ animal encontrava-se próximo a árvores na praça pública do bairro Ipiranga.

Caso 05 - Molossus molossus - Na manhã do dia 31/07/2010, foi localizado na praça Academia das Cidades, bairro Pajeú, um espécime caído no chão de uma sala, tentando locomover-se com dificuldade. O fato foi comunicado a Secretaria de Saúde que realizou a captura do morcego de imediato.

Caso 06 - Myotis lavali - Em 02/08/ 2010, às 14h00min, um agente comunitário de saúde localizou em uma passarela da Praça Antônio Jorge, no bairro Ipiranga, um morcego caído no chão, ainda vivo e tentando se deslocar com dificuldades.

Caso 07 - Molossus molossus - No dia 11/02/2011, em uma residência próxima a praça do Ipiranga (local com histórico de positividade para raiva), um macho adulto da espécie foi encontrado vivo e pendurado em uma toalha estendida no quintal da residência. Um agente de endemias que residia próximo ao local foi chamado e fez a coleta do espécime.

Caso 08 - Molossus molossus - Em 18/02/2011, no Centro, um morcego voava no horário da manhã e se abrigou em uma residência, não conseguindo mais alçar voo e locomovendo-se sem coordenação. Foi capturado por um morador e em seguida recolhido para a Vigilância Sanitária do município.

Caso 09 - Molossus molossus - Em 04/04/2011, no bairro São João, um morcego foi encontrado no chão de uma residência no horário vespertino, caído de um abrigo no forro. O quiróptero não conseguia deslocar-se, foi recolhido pelo proprietário do imóvel e encaminhado para diagnóstico. Na residência existiam animais domésticos (cão e gato) que, segundo o proprietário, não tiveram contato com o morcego.

Caso 10 - Glossophaga soricina - No dia 04/06/2011, foi realizada uma coleta no Centro, em um depósito utilizado para guardar antigos pertences dos proprietários. O local servia de abrigo para filostomídeos que não foram capturados (provavelmente glossofagíneos). No espaço foi encontrado um espécime morto, pendurado no teto, que após a coleta seguiu para análise rábica. 
Caso 11 - Molossus molossus - Em 30/12/2011, pelo horário da manhã, um morcego foi encontrado em um supermercado do bairro Pajeú. Uma funcionária que afastava caixas próximas à parede do depósito assustou-se por sentir um animal sobre o seu pé e, ao movimentá-lo, sofreu uma mordida na região. A vítima foi conduzida ao hospital para iniciar a profilaxia pós exposição. $\mathrm{O}$ animal foi coletado e testou positivo. $\mathrm{O}$ resultado foi comunicado a vítima, que prosseguiu o tratamento pósexposição.

\section{Discussão}

Investigar a ocorrência de raiva em morcegos no Brasil, em diferentes regiões e nas áreas urbanas e rurais, é de fundamental importância para o monitoramento da raiva e por consequência na descrição de ações que possam mitigar futuros casos. O Brasil é considerado um país com elevada diversidade de morcegos, albergando mais de 180 espécies (Garbino et al., 2020), muitas das quais já diagnosticadas com raiva no país (Sodré et al., 2010; Fahl et al., 2015). Pode-se ainda salientar que o perfil epidemiológico da transmissão da raiva a humanos no país modificou, predominando os casos a partir da transmissão por morcegos (Vargas et al., 2019).

Com exceção de $M$. lavali, todas as espécies aqui registradas já foram diagnosticadas com raiva em diferentes regiões do Brasil (Sodré et al., 2010; Fahl et al., 2015). O alto número de morcegos positivos no município, alcançado em um curto intervalo de tempo, pode ser explicado pela intensificação do monitoramento de morcegos na cidade e das campanhas de conscientização, que repercutiram em um maior envolvimento da população local, aumentado às denúncias de morcegos encontrados em condições atípicas.

O elevado número de M. molossus encontrados com o vírus rábico pode estar relacionado ao fato da espécie ser abundante na Caatinga (Oliveira et al., 2003) e em construções humanas (Pacheco et al., 2010. No município M. molossus apresentou alta taxa de ocorrência em abrigos antrópicos (Vilar et al., 2016). Estes fatores aumentam as chances dos animais serem encontrados pela população caso estejam doentes e apresentando comportamentos atípicos (atividade de voo diurna, caídos no chão, adentrando residências pousados em pontos de fácil acesso entre outros comportamentos não relacionados a espécie) pela população. Molossus molossus foi diagnosticada positiva para a raiva em Pernambuco pela primeira vez em 2010, no Recife (Silva et al., 2011) e posteriormente na cidade de Moreno (Albuquerque et al., 2013), que registraram ainda Eptesicus fuscus (Beauvois, 1796). No estado, dentre as espécies não hematófagas, há registro de positividade para Artibeus planirostris (Spix, 1823) em Olinda (Silva et al., 2010). Com os resultados apurados no presente estudo podemos acrescentar G. soricina e M. lavali a lista de espécies de morcegos não hematófagos positivas para raiva em Pernambuco.

Relatos de casos de agressões por morcegos não hematófagos a humanos podem ocorrer, porém em menor intensidade quando comparado a agressões por cães e gatos (Dantas-Torres \& Oliveira-Filho, 2007), entretanto não se pode desconsiderar o risco de transmissão do vírus da raiva por morcegos não hematófagos a humanos. Desta forma, segundo Duarte et al., (2021) é importante que os profissionais da saúde recebam informações detalhadas, que possam contribuir nas ações de vigilância e controle da raiva e na prevenção de novos casos além de campanhas educacionais voltadas a população com foco principalmente na raiva em animais silvestres. Além disso, envolver na atuação equipes multiprofissionais para melhor analisar as ações de manejo, viabilizando assim a implementação de atividades que minimizem a presença de morcegos se abrigando em áreas urbanas (Melo et al., 2021).

\section{Conclusão}

A necessidade de acompanhamento constante dos registros de morcegos encontrados em condições atípicas diminui os riscos de surtos de raiva em humanos ou animais domésticos. Além disso, campanhas educativas são ferramentas 
importantes nesses monitoramentos, como no caso 11. A gravidade da lesão causada por uma mordedura defensiva de morcego pode ser desconsiderada pela população. Muitos morcegos são pequenos e alguns atingem apenas $5 \mathrm{~g}$ quando adultos, ocasionando pequenas lesões, mas suficientes para inoculação do Lyssavirus caso o animal esteja infectado.

Como forma de minimizar os riscos futuros de transmissão de raiva por quirópteros a humanos deve-se manter um programa de Monitoramento da Raiva em morcegos no Município, tanto na zona rural quanto na zona urbana, direcionado a espécies hematófagas e não hematófagas e capacitar equipes na captura, manejo e identificação de morcegos. É essencial para o programa, implantar ações de educação ambiental, direcionadas a comunidade em geral e nas escolas, com o intuito de informar sobre os cuidados necessários ao encontrar um morcego, a profilaxia adotada após uma agressão e principalmente sobre a importância desses animais para o ecossistema. O desenvolvimento de trabalhos voltados ao diagnóstico da raiva em outras espécies, principalmente as silvestres, é de fundamental importância para melhor entender o ciclo da raiva na região.

\section{Referências}

Albuquerque, P., Silva, L. A. M., Cunha, M. C., Silva, C. J., Machado, J. L. M., Melo, M. L. \& Alencar, V. I. B. (2013). Vigilância epidemiológica da raiva em morcegos no Município de Moreno, Pernambuco, Brasil. Revista Biociências, 18(2), 5-13.

Brasil. Ministério da Saúde. (2008). Manual de Diagnóstico Laboratorial da Raiva. Ministério da Saúde.

Dantas-Torres, F. \& Oliveira-Filho, E. F. D. (2007). Human exposure to potential rabies virus transmitters in Olinda, State of Pernambuco, between 2002 and 2006. Revista da Sociedade Brasileira de Medicina Tropical, 40(6), 617-21.

Díaz, M. M., Aguirre, L. F., Barquez, R. M. (2011) Clave de identificación de los murciélagos del cono sur de Sudamérica. Cochabamba, Centro de Estudios de Biología Teórica y Aplicada

Díaz, M. M., Solari, V., Aguirre, L. F., Aguiar, L., \& Barquez, Y. R. M. (2016). Clave de identificación de los murciélagos de Sudamérica/Chave de indentifição dos morcegos da América do Sul. Publicación Especial PCMA Nro 2. Editorial Magna Publicaciones

Duarte, N. F. H., Pires Neto, R. Da J., Viana, V. F., Feijão, L. X., Abreu, K. G. de, Melo, I. M. L. A., Sousa, A. Q., Alencar, C. H., Heukelbach, J.2021. Epidemiologia da raiva humana no estado do Ceará, 1970 a 2019. Epidemiologia e Serviços de Saúde, 30(1), e2020354.

Escobar, L. E., Peterson, T. A., Favi, M., Yung, V. \& Medina-Vogel, G. (2015). Bat-Borne Rabies in Latin America. Revista do Instituto de Medicina Tropical de São Paulo, 57(1), 63-72.

Fahl, W. O., Garcia, A. I. E., Achkar, S. M., Mori, E., Asano, K. M., Iamamoto, K. \& Scheffer, K. C. (2015). Rabia transmitida por murciélagos en Brasil. Acta Biológica Colombiana, 20(3), 21-35.

Ferreira, G. da S, Oliveira, R. A., Galvão, L. B., Paula, E. M. N, Melo, P. de C., Romani, A. F., Ramos, D. G. de Souza, Amaral, A. V. C. do, Cruz, C. de A., Souza, D. B. de \& Bartoli, R. B. M. 2020. Taxa de cobertura antirrábica em cães e gatos nos anos de 2010 a 2018 nas campanhas municipais de Jataí - Goiás, Brasil Research, Society and Development, 9(7), e351974223

Fooks, A.R., Cliquet, F., Finke, S., Freuling, C., Hemachudha, T., Mani, R.S., Müller, T., Nadin-Davis, S., Picard-Meyer, E., Wilde, H. \& Banyard, A.C. (2017). Rabies. Nature Reviews Disease Primers, 3:17091. doi: 10.1038/nrdp.2017.91.

Garbino, G.S.T., Gregorin, R., Lima, I.P., Loureiro, L., Moras, V., Moratelli, R., Nogueira, M.R., Pavan, A.C., Tavares, V.C. Nascimento, M.C. Do \& Peracchi, A.L. 2020. Updated checklist of Brazilian bats: versão 2020. Comitê da Lista de Morcegos do Brasil-CLMB. Sociedade Brasileira para o Estudo de Quirópteros (Sbeq). 〈https://www.sbeq.net/lista-de-especies>

Gardner, A. L. (2007). Mammals of South America: Marsupials, Xenarthrans, Shrews, and Bats. Chicago: University of Chicago Press.

Gregorin, R. \& Taddei V. A. 2002. Chave artificial para a identificação de Molossídeos brasileiros (Mammalia, Chiroptera). Mastozoologia Neotropical, 9(1), $13-32$

IBGE - Instituto Brasileiro de Geografia e Estatística (2020). Panorama: São José do Egito. <https://cidades.ibge.gov.br/brasil/pe/sao-jose-doegito/panorama>.

Kotait, I., Carrieri, M. L., Carnieli Júnior, P., Castilho, J. G., Oliveira, R. N., Macedo, C. I., Ferreira, K. C. S. \& Achkar, S. M. (2007). Reservatórios silvestres do vírus da raiva: um desafio para a saúde pública. Boletim Epidemiológico Paulista, 4(40), 02-08.

Kotait, I., Nogueira-Filho, V. S., Souza, M. C. A. M., Carrieri, M. L., Gomes, M. N., Peres, N. F. (2010). Manual Técnico do Instituto Pasteur: manual de controle da raiva dos herbívoros. In Manual Técnico do Instituto Pasteur: manual de controle da raiva dos herbívoros (pp. 58-p).

Lopes, T. V, Souza, J. G. da S. G., Urtiga, D G C, Costa, L B. da S, Virgolino, M. S., Schons, S. de V \& Souza, F. A. 2021 Estudo retrospectivo da prevalência de raiva bovina no Estado de Rondônia e sua distribuição entre os anos de 2009 e 2018. Research, Society and Development, 10(9), e35510918038,

Melo, M. A., Braga, D. de A., Mansho, W., Carvalho, R. R., Oliveira, D. C. de \& Rosa, A. R. 2021. Morcegos urbanos de Guarulhos: alta riqueza de espécies e dominância de espécies ecologicamente flexíveis reveladas a partir de dados de monitoramento da raiva. Iheringia, Série Zoologia, 111, e2021009 
Research, Society and Development, v. 10, n. 10, e378101018971, 2021

(CC BY 4.0) | ISSN 2525-3409 | DOI: http://dx.doi.org/10.33448/rsd-v10i10.18971

Miranda, J. M. D., Bernardi I P \& Passos F C. (2011) Chave ilustrada para determinação dos morcegos da Região Sul do Brasil.

Moratelli R, Peracchi, A L, Dias D \& Oliveira J A De. 2011. Geographic variation in South American populations of Myotis nigricans (Schinz, 1821) (Chiroptera, Vespertilionidae), with the description of two new species. Mammalian Biology 76:592-607.

Moratelli, R. \& Wilson, D. E. (2013). Distribution and natural history of Myotis lavali (Chiroptera, Vespertilionidae). Journal of Mammalogy, 94(3), 650-656.

Oliveira, J. A., Gonçalves, P. R. \& Bonvicino, C. R. Mamíferos da Caatinga. In: Leal, I. R., Tabarelli, M., Silva, J. M. C. (eds.). (2003). Ecologia e Conservação da Caatinga. Recife, Editora Universitária UFPE.

Pacheco, S. M., Sodré, M., Gama, A. R., Bredt, A., Cavallini-Sanches, E. M., Marques, R. V., Guimarães, M. M. \& Bianconi, G. (2010). Morcegos urbanos: status do conhecimento e plano de ação para a conservação no Brasil. Chiroptera Neotropical, 16(1), 630-647.

Quevedo, L De S, Hugen, G. F. G. P, Morais, R. M., \& Quevedo, P. S. (2020). Aspectos epidemiológicos, clínico-patológicos e diagnóstico de raiva em animais de produção: Revisão. PUBVET 14(11), 1-11.

Silva, E. M. V. G., Silva, R. R., Silva, L. A. M., Melo, E. H., Pontes, C., Marcondes, M. \& Miranda, T. (2010). Primeiro registro de raiva em morcego frugívoro em área urbana de Olinda, Pernambuco, Brasil. Chiroptera Neotropical, 16(1), 149-151.

Silva, L. A. M., Machado, J. L. M., Melo, M. L., Alencar, V. I. B., Melo, R. S., Andrade, L. P. \& Silva, E. M. V. G. (2011). Rabies virus in Molossus molossus (Chiroptera: Molossidae) in the state of Pernambuco, Northeastern Brazil. Revista da Sociedade Brasileira de Medicina Tropical, 44(4), 526-527.

Sodré, M. M., Gama, A. R., \& Almeida, M. F. (2010). Updated list of bat species positive for rabies in Brazil. Revista do Instituto de Medicina Tropical, $52(2), 75-81$.

Vargas, A., Romano, A. P. M., \& Merchán-Hamann, E. 2019. Raiva humana no Brasil: Estudo descritivo, 2000-2017. Epidemiol. Serv. Saude 28(2), e2018275

Vilar, E. M., Silva-Filho, T. P., Silva, R. R., Gomes, E. S. \& Silva, L. A. M. (2016). Abrigos antrópicos utilizados por morcegos no semiárido pernambucano. Boletim da Sociedade Brasileira de Mastozoologia, 77, 79-86.

Vizotto, L. D. \& Taddei, V. A. (1973). Chave para identificação de quirópteros brasileiros. Revista da Faculdade de Filosofia Ciências e Letras São José do Rio Preto. Boletim de Ciências, 1, 1-72. 